\title{
Preoperative lymphopenia is a predictor of postoperative adverse outcomes in children with congenital heart disease
}

\author{
Antonio G. Cabrera, MD, ${ }^{\mathrm{a}}$ Umesh Dyamenahalli, MD, ${ }^{\mathrm{b}}$ Jeffrey Gossett, MS, ${ }^{\mathrm{b}}$ Parthak Prodhan, MBBS, ${ }^{\mathrm{b}}$ \\ W. Robert Morrow, MD, ${ }^{b}$ Michiaki Imamura, MD, $\mathrm{PhD},{ }^{\mathrm{c}}$ Robert D. B. Jaquiss, $\mathrm{MD},{ }^{\mathrm{c}}$ and \\ Adnan T. Bhutta, MBBS ${ }^{b}$
}

\begin{abstract}
Objective: Lymphopenia is a predictor of adverse clinical outcomes in adults with various systemic diseases. We hypothesized that preoperative absolute lymphopenia (absolute lymphocyte count of less than $3000 \mathrm{cells} / \mu \mathrm{L}$ ) is associated with adverse postoperative outcomes in children with congenital heart disease undergoing corrective or palliative surgery on cardiopulmonary bypass during the first 2 years of life.
\end{abstract}

\begin{abstract}
Methods: A retrospective single center cohort study was performed. Categorical variables were analyzed with the $\chi^{2}$ test. Preoperative variables were analyzed with logistic and linear regression analysis to determine whether they were associated with adverse outcomes.
\end{abstract}

\begin{abstract}
Results: Analysis was performed on 280 patients, of whom 124 were female and 156 were male. Seventy-one patients were neonates ( $\leq 30$ days) at the time of the operation. Ninety patients had an absolute lymphocyte count of less than 3000 cells $/ \mu$ L before the operation. Regression models showed that RACHS- 1 categories 5 and 6 , age, and preoperative lymphopenia were significantly associated with postoperative mortality $(P<.0006)$. Within RACHS-1 groups, lymphopenia remained a significant predictor of mortality for patients in RACHS categories 3 and 4. Lymphopenia and age were associated with longer length of stay and length of mechanical ventilation within RACHS categories 1 to $4(P<.05)$. Preoperative lymphopenia was the only predictor of use of postoperative nitric oxide $(P<.05)$.
\end{abstract}

Conclusions: Preoperative lymphopenia is a predictor of adverse postoperative outcomes in children with congenital heart disease who undergo a corrective or palliative procedure with cardiopulmonary bypass during the first 2 years of life.

Lymphocytes play a central role in both innate and adaptive immunity. ${ }^{1}$ A decrease in absolute lymphocyte count (ALC) secondary to congenital or acquired immunodeficiency is associated with increased susceptibility to infections. ${ }^{2,3}$ Lymphocyte cell number and distribution are distinctly different in children from values for adults. In adults, an ALC of less than 1000 cells $/ \mu \mathrm{L}$ is considered diagnostic of lymphopenia. ${ }^{4}$ By contrast, in children less than 2 years of age, an ALC of 3000 cells $/ \mu \mathrm{L}$ corresponds to the fifth percentile of the ALC. . $^{4-7}$

A decrease in ALC has been reported in acutely and critically ill adult patients with systemic inflammatory response syndrome $^{8}$ and has also been noted in more chronic, stressful conditions such as congestive heart failure in adult patients. ${ }^{9-11}$ Profound B lymphocyte and CD4 positive T cell

From the Department of Pediatrics, ${ }^{\text {a }}$ University of Tennessee, Memphis/Le Bonheur Children's Medical Center, Memphis, Tenn, and the Departments of Pediatrics ${ }^{b}$ and Surgery, ${ }^{\mathrm{c}}$ University of Arkansas for Medical Sciences/Arkansas Children's Hospital, Little Rock, Ark.

Received for publication Nov 25, 2008; revisions received April 3, 2009; accepted for publication June 14, 2009; available ahead of print July 30, 2009.

Address for reprints: Adnan T. Bhutta, MBBS, FAAP, Assistant Professor, University of Arkansas for Medical Sciences, 1 Children's Way, Slot 512, Little Rock, AR 72202 (E-mail: bhuttaadnant@uams.edu).

J Thorac Cardiovasc Surg 2009; 138:1172-9

$0022-5223 / \$ 36.00$

Copyright (c) 2009 by The American Association for Thoracic Surgery

doi:10.1016/j.jtcvs.2009.06.016 loss secondary to apoptosis is thought to contribute to the immunosuppression seen in critically ill patients. ${ }^{12}$ Prolonged lymphopenia associated with critical illness can significantly increase risk for nosocomial infections and death. $^{9-11,13}$

We observed that many patients in our pediatric cardiovascular intensive care unit had low ALCs preoperatively. This trend was especially noticeable in neonates and infants with complex congenital heart disease, who were frequently noted to have ALCs below 3000 cells $/ \mu \mathrm{L}$. Bocsi and associates ${ }^{14}$ have demonstrated that in children with congenital heart disease aged 3 to 18 years, the preoperative decrease in lymphocyte percentage was one of the predictors of postoperative edema and effusions. However, there are no published studies assessing the risk of lymphopenia in younger children with congenital heart disease.

We sought to determine whether preoperative absolute lymphopenia (ALC $<3000$ cells $/ \mu \mathrm{L}$ ) was an independent predictor of adverse postoperative outcomes in children less than 2 years of age undergoing surgery for complex congenital heart disease.

\footnotetext{
METHODS

Patients

We conducted a retrospective review of medical records of children undergoing cardiac surgery at Arkansas Children's Hospital from January
} 


$$
\text { Abbreviations and Acronyms }
$$

$\begin{array}{ll}\text { ALC } & =\text { absolute lymphocyte count } \\ \text { CI } & =\text { confidence interval } \\ \text { OR } & =\text { odds ratio } \\ \text { RACHS-1 } & \text { Risk Adjusted classification for } \\ & \text { Congenital Heart Surgery } \\ \text { ROC } & =\text { receiver operating characteristic }\end{array}$

2003 to June 2005. The study protocol was approved by the Institutional Review Board at the University of Arkansas for Medical Sciences and waiver for obtaining informed consent was granted. We included all children less than 2 years of age who were undergoing their first cardiac surgical procedure with cardiopulmonary bypass and who had preoperative complete blood count with differential available. We excluded children under 2 years of age who were undergoing procedures without cardiopulmonary bypass or those undergoing orthotopic heart transplantation, inasmuch as heart transplantation is not included the Risk Adjusted classification for Congenital Heart Surgery (RACHS-1) used.

We identified 280 children who met the inclusion criteria and did not meet the exclusion criteria. Data from these patients were extracted from hospital chart, an electronic surgical database, and the laboratory data system and were reviewed retrospectively.

\section{Data Collection}

Preoperative variables included patient's age, sex, birth weight, cardiac diagnoses including presence of chromosomal or structural anomalies, use of preoperative inotropes, need for preoperative mechanical ventilation, need for preoperative extracorporeal life support, preoperative laboratory values obtained a day before the operation including complete blood count with differential, serum albumin, blood urea nitrogen, and serum creatinine. Low birth weight was defined as less than $2500 \mathrm{~g}$. Intraoperative variables included cardiopulmonary bypass time, crossclamp time, and RACHS-1 surgical procedure category.

The RACHS-1 method is a consensus-based risk adjustment classification that assesses surgical complexity and organizes surgical procedures into 6 categories; relatively simple surgical procedures, such as repair of an atrial septal defect, are assigned category 1 and complex operations, such as Norwood palliation for hypoplastic left heart syndrome, are assigned the highest risk category of 6 . The RACHS-1 classification has been shown to reflect mortality and length of stay in large pediatric heart surgery populations. ${ }^{15-17}$

\section{Outcomes}

The primary outcome measure was survival to hospital discharge for patients. Other postoperative outcomes studied were length of hospital stay, length of mechanical ventilation, presence of renal dysfunction as defined by the RIFLE criteria (Risk, Injury, Failure, Loss, End-stage kidney disease) of a $50 \%$ increase in serum creatinine value, ${ }^{18}$ need for dialysis, use of nitric oxide, use of extracorporeal life support, use of hydrocortisone for pressorresistant hypotension, duration of chest tube retention, use of low fat formula as a surrogate for chylous effusion in the postoperative period, level of positive end-expiratory pressure and inotrope score on the first postoperative day, total number of bacterial cultures (blood, urine, and respiratory) sent in the postoperative period, and number of positive cultures in the postoperative period.

\section{Statistical Analysis}

Our statistical analysis was aimed at studying the contribution of the preoperative variables on the primary and secondary outcomes noted above. For the purposes of analysis, study subjects were assigned to one of two groups on the basis of their preoperative ALC counts: group 1 patients $(\mathrm{n}=90)$ had an ALC of 3000 cells $/ \mu \mathrm{L}$ or less and group 2 patients $(\mathrm{n}=$ 190) had an ALC of greater than 3000 cells $/ \mu$ L. On the basis of RACHS1 category, 3 levels of surgical risk were defined: low risk, RACHS- 1 categories 1 and 2; medium risk, RACHS-1 categories 3 and 4; high risk, RACHS- 1 categories 5 and 6 .

We performed an inverse square root transformation of age because the relationship between age and mortality is complex in that mortality is increased in the youngest infants, possibly as a result of the complexity of lesions and of the surgical interventions needed in the early neonatal period. ${ }^{19}$ All patients receiving inotropes in the postoperative study period were assigned an inotrope score based on a published reference. ${ }^{20}$ The following variables were analyzed in a dichotomous manner: serum albumin, low or normal based on the lower limit of the clinical laboratory's reference range $(<2.6 \mathrm{gm} / \mathrm{dL})$; serum creatinine and blood urea nitrogen, normal or high based on the upper limit of the laboratory normal range $(\leq 0.6 \mathrm{mg} / \mathrm{dL}$ and $\leq 18 \mathrm{mg} / \mathrm{dL}$ ); and presence of a known genetic or chromosomal/genetic abnormality or a congenital abnormality not associated with known genetic defect.

The $\chi^{2}$ test, $t$ test, or Wilcoxon rank sum test was used to test for differences in the preoperative variables and in the postoperative outcomes between the lymphopenic and nonlymphopenic patients. The univariate logistic regression results are presented as odds ratios, favoring lymphopenic or control with their $95 \%$ confidence interval (CI). Binary outcomes were analyzed by multiple stepwise logistic regression analysis. All preoperative variables including transformed age, gender, RACHS- 1 category (low, 1-2; medium, 3-4, high, 6), presence or absence of genetic and/or congenital anomaly, presence of low birth weight $(<2500 \mathrm{~g})$, need for preoperative mechanical ventilation, inotrope score, presence of low serum albumin level, high creatinine level, high blood urea nitrogen level, and lymphopenia (ALC $<3000$ cells $/ \mu \mathrm{L}$ ) were included in the stepwise multiple logistic regression models. The preoperative variables included in the analysis are based on variables identified by Jenkins and associates ${ }^{16}$ as significant clinical risk factors for mortality ${ }^{16}$ and preoperative variables associated with increased postoperative length of stay. ${ }^{21,22} \mathrm{We}$ added preoperative albumin inasmuch as we had observed before our study that most of the patients who were lymphopenic also had low serum albumin concentrations. Coefficients were tested for significance for inclusion or elimination from the model using the Wald test or likelihood-ratio test. The goodness of fit of the model fit using the stepwise procedure was assessed by the Hosmer-Lemshow goodness-of-fit test. When included in the multivariable model with risk category, the single factor that provided the most additional predictive information about mortality was retained in the model; the remaining factors were then re-evaluated. The process was repeated until none of the remaining factors contributed significantly to the prediction of mortality.

For postoperative mortality, the area under the receiver operating characteristic (ROC) curves was used to assess the discriminatory value of the fitted logistic regression models. Cox proportional hazards models were used to analyze the length of stay and length of mechanical ventilation with censoring of patients who died at the time of death.

Data were entered in customized Access Database (Microsoft Corporation, Redmond, Wash) and analyzed with either SAS version 9 (SAS Institute, Inc, Cary, NC) or STATA version 10 (Stata Corporation, College Station, Tex) statistical packages.

\section{RESULTS}

Baseline preoperative characteristics of the 2 groups are outlined in Table 1. Stepwise logistic regression analysis showed that group 1 patients were more likely to have low preoperative albumin levels (odds ratio [OR] 2.3 with $95 \%$ CI 1.1-4.7), higher serum creatinine concentrations (OR, 4.1; 95\% CI, 2.1-8.4), presence of genetic or 
TABLE 1. Baseline characteristics

\begin{tabular}{|c|c|c|c|}
\hline & Group $1(\mathrm{ALC}<3000) ; \mathrm{n}=90$ & Group $2($ ALC $>3000) ; n=190$ & $P$ value \\
\hline Age at operation (mean days \pm SD) & $165 \pm 203$ & $208 \pm 184$ & .09 \\
\hline$\leq 30$ days $(\%)$ & 43 & 17 & \\
\hline 31 days to 1 year $(\%)$ & 40 & 63 & \\
\hline 1 to 2 years $(\%)$ & 17 & 18 & \\
\hline Male sex $(\%)$ & 64 & 52 & .04 \\
\hline White $(\%)$ & 49 & 64 & .017 \\
\hline African American (\%) & 42 & 26 & .01 \\
\hline Chromosomal/genetic or congenital anomaly ( $\%)$ & 29 & 23 & .37 \\
\hline Trisomy 21 & $57 \%$ & $54 \%$ & \\
\hline DiGeorge syndrome & $8 \%$ & $2 \%$ & \\
\hline Turner syndrome & $8 \%$ & $0 \%$ & \\
\hline Noonan syndrome & $4 \%$ & $2 \%$ & \\
\hline Other genetic anomaly & $4 \%$ & $5 \%$ & \\
\hline Other congenital anomaly & $19 \%$ & $37 \%$ & \\
\hline Percent LBW & $16 \%$ & $6 \%$ & .016 \\
\hline Albumin $(\mathrm{g} / \mathrm{dL}$, mean $\pm \mathrm{SD})$ & $3.2 \pm 0.6$ & $3.7 \pm 0.6$ & $<.0001$ \\
\hline Creatinine $(\mathrm{mg} / \mathrm{dL}$, mean $\pm \mathrm{SD})$ & $0.5 \pm 0.2$ & $0.4 \pm 0.1$ & .00036 \\
\hline Hematocrit $(\%$,mean $\pm \mathrm{SD})$ & $40.6 \pm 6.6$ & $38.3 \pm 5.6$ & .002 \\
\hline WBC count $\left(\right.$ cell $/ \mathrm{mm}^{3}$, mean $\left.\pm \mathrm{SD}\right)$ & $8.7 \pm 4.3$ & $10.6 \pm 3.6$ & .0004 \\
\hline Platelet count $\left(\mathrm{mm}^{3}\right.$, mean $\left.\pm \mathrm{SD}\right)$ & $273.1 \pm 99.7$ & $371.1 \pm 115.5$ & $<.0001$ \\
\hline Percent needing preoperative mechanical ventilation & 21.70 & 12.40 & .01 \\
\hline Inotrope score $($ mean $\pm \mathrm{SD})$ & $0.97 \pm 2.7$ & $0.27 \pm 1.6$ & .024 \\
\hline RACHS-1 & & & $<.0001$ \\
\hline No. in RACHS-1 category $1(\%)$ & $0(0)$ & $6(3)$ & \\
\hline No. in RACHS-1 category $2(\%)$ & $26(29)$ & $105(52)$ & \\
\hline No. in RACHS-1 category $3(\%)$ & $33(37)$ & $54(28)$ & \\
\hline No. in RACHS-1 category $4(\%)$ & $19(21)$ & $16(8)$ & \\
\hline No. in RACHS-1 category $6(\%)$ & $12(13)$ & $9(5)$ & \\
\hline
\end{tabular}

$\overline{A L C}$, Absolute lymphocyte count; $L B W$, Low birth weight ( $<2500 \mathrm{~g}) ; S D$, standard deviation; $W B C$, white blood cell count; $R A C H S$, Risk Adjusted classification for Congenital Heart Surgery.

congenital anomalies (OR, 2.1; 95\% CI, 1.1-3.8), and higher inotrope scores (OR 1.2 with 95\% CI 1.1-1.5).

Postoperative outcomes are shown in Table 2. Stepwise regression analysis showed that preoperative lymphopenia was a predictor of postoperative mortality, length of hospital stay, length of mechanical ventilation, and postoperative nitric oxide use. It was not a predictor for the other outcomes shown in Table 2.

TABLE 2. Univariate analysis of postoperative outcomes

\begin{tabular}{|c|c|c|c|c|}
\hline Postoperative outcome variables & Group I (ALC < 3000) & Group $2(A L C \geq 3000)$ & $\begin{array}{c}\text { Odds ratio for } \\
\text { lymphopenia with } 95 \% \text { CI }\end{array}$ & $P$ value \\
\hline Percent hospital mortality & 14.4 & 1.1 & $15.9(3.5-72)$ & .001 \\
\hline Median length of stay $(95 \% \mathrm{CI})$ & $17(13-23)$ & $7(7-9)$ & $1.0(1.0-1.02)$ & .02 \\
\hline $\begin{array}{l}\text { Median length of mechanical } \\
\text { ventilation }(95 \% \mathrm{CI})\end{array}$ & $4(3-6.6)$ & $2(1-2)$ & $1.0(1.0-1.1)$ & .001 \\
\hline Renal dysfunction (yes/no) (\%) & 65.2 & 64.6 & $1.0(0.7-1.7)$ & .92 \\
\hline Need for dialysis (yes/no) $(\%)$ & 17.8 & 11.6 & $1.7(0.8-3.3)$ & .16 \\
\hline Postop ECLS (\%) & 12.2 & 3.7 & $3.6(1.4-9.7)$ & .01 \\
\hline Postop inhaled nitric oxide $(\%)$ & 22.2 & 5.3 & $5.1(2.9-11.5)$ & .0001 \\
\hline Mean chest tube duration (d) & $5.6 \pm 6.5$ & $3.7 \pm 3.3$ & $1.1(1.0-1.2)$ & .005 \\
\hline Hydrocortisone use in the postop period $(\%)$ & 13.3 & 4.2 & $3.5(1.4-8.9)$ & .009 \\
\hline Chylous effusion in the postop period $(\%)$ & 22.2 & 8.4 & $3.1(1.5-6.3)$ & .002 \\
\hline Level of PEEP on postop day 1 & $6.7 \pm 2$ & $6.3 \pm 1.7$ & $1.1(0.98-1.3)$ & .08 \\
\hline Inotrope score on postop day 1 & $13.1 \pm 10.7$ & $9.4 \pm 6.5$ & $1.1(1.0-1.1)$ & .002 \\
\hline Positive cultures (yes/no) (\%) & 35.6 & 27.0 & $1.5(0.9-2.6)$ & .14 \\
\hline Number of cultures sent & $14 \pm 25$ & $7 \pm 17$ & $1.02(1.0-1.03)$ & .01 \\
\hline
\end{tabular}

$\overline{A L C}$, Absolute lymphocyte count; $C I$, confidence interval; $E C L S$, extracorporeal life support; $P E E P$, positive end-expiratory pressure. 
TABLE 3. Multivariable model for prediction of postoperative mortality from preoperative variables

\begin{tabular}{|c|c|c|c|c|}
\hline & \multicolumn{2}{|c|}{ Full model } & \multicolumn{2}{|c|}{ Stepwise fit } \\
\hline & Odds ratio $(95 \% \mathrm{CI})$ & Wald $P$ value & Odds ratio $(95 \% \mathrm{CI})$ & Wald $P$ value \\
\hline Lymphopenia (ALC < 3000 cells $/ \mathrm{mm}^{3}$ ) & $9.3(1.8-48)$ & .009 & $10.6(2.3-50)$ & .003 \\
\hline RACHS-1 medium-risk vs low-risk groups & $3.7(0.4-36.5)$ & .339 & & \\
\hline RACHS-1 high-risk vs low-risk groups & $17.1(1.4-203.9)$ & .082 & $4.2(1.1-15.1)$ & .031 \\
\hline Transformed age & $1.1(0.9-1.4)$ & .043 & $1.2(1-1.4)$ & .011 \\
\hline Male gender & $0.6(0.2-2.3)$ & .337 & & \\
\hline Need for preop mechanical ventilation & $0.3(0-1.7)$ & .116 & & \\
\hline $\begin{array}{l}\text { Presence of chromosomal/genetic congenital } \\
\text { anomaly (yes vs no) }\end{array}$ & $1(0.2-4.7)$ & .707 & & \\
\hline Preoperative need for inotropes & $1.2(1-1.6)$ & .191 & & \\
\hline Presence of low albumin $(<2.6 \mathrm{~g} / \mathrm{dL})$ & $2.3(0.6-9.4)$ & .637 & & \\
\hline High creatinine $(>0.6 \mathrm{mg} / \mathrm{dL})$ & $1.2(0.3-5.7)$ & .696 & & \\
\hline High BUN (>18 mg/dL) & $2.2(0.3-16.2)$ & .457 & & \\
\hline
\end{tabular}

$C I$, Confidence interval; $A L C$, absolute lymphocyte count; RACHS, Risk Adjusted classification for Congenital Heart Surgery; BUN, blood urea nitrogen.

\section{Mortality}

A multivariate model showed that patient's age, presence of lymphopenia, and high risk category were predictive of mortality (see Table 3) in our patients with the area under the ROC of 0.90 . When data were analyzed within risk categories, lymphopenia was a statistically significant predictor of mortality in medium risk patients. Although mortality was also higher for lymphopenic patients undergoing low-risk and high-risk procedures, the difference in mortality did not achieve statistical significance (see Figure 1).

\section{Length of Hospital Stay}

Age at the time of the operation $(P<.0001)$ and lymphopenia $(P<.0001)$ were significant predictors for length of hospital stay in a multivariate analysis (Figure $2, A$ ). The median length of stay was 17 days (CI, 13.23) for lymphopenic patients and 7 days (CI, 7.9) for nonlymphopenic patients. By 60 days only $2.2 \%$ of nonlymphopenic patients had remained in the hospital compared with $14.87 \%$ in the lymphopenic group. When data were analyzed within risk categories, lymphopenic patients were consistently noted to have longer lengths of stay (Figure 2,B). The presence of lymphopenia and younger age at operation remained significant predictors of length of stay for low- and medium-risk groups $(P<.05)$, and lymphopenia almost reached significance as a predictor for length of stay in the high-risk group $(P=.08)$.

\section{Effect on Respiratory Support}

In a multivariate analysis, preoperative lymphopenia, along with transformed age, risk category, and presence of chromosomal or congenital anomaly, were predictive of increased length of mechanical ventilation $(P<.05)$ (see Figure $3, A$ ). When data were analyzed within risk categories, lymphopenic patients were consistently noted to have longer duration of mechanical ventilation (see Figure 3, $B$ ). Preoperative lymphopenia and age at operation remained significant predictors of duration of mechanical ventilation in low- and medium-risk groups $(P<.05)$.Preoperative lymphopenia did not reach significance as a predictor of length of mechanical ventilation in the high-risk group $(P=.08)$. Preoperative lymphopenia remained the only predictor of postoperative use of nitric oxide $(P<.05)$.

\section{DISCUSSION}

In this retrospective review of children undergoing cardiac surgery before the age of 2 years, preoperative lymphopenia was found to be an independent risk factor for postoperative mortality, increased hospital stay, and increased postoperative respiratory support including the sole predictor of nitric oxide use. We chose to examine the total number of cultures sent as a surrogate for febrile illness in our patients. Although the univariate analysis showed an increase in the total number of cultures sent in lymphopenic patients, no statistical difference was noted in the proportion of positive bacterial cultures. This could be explained by the fact that lymphopenic patients are at risk for the development of viral infections that would not have been detected by routine bacterial or fungal cultures.

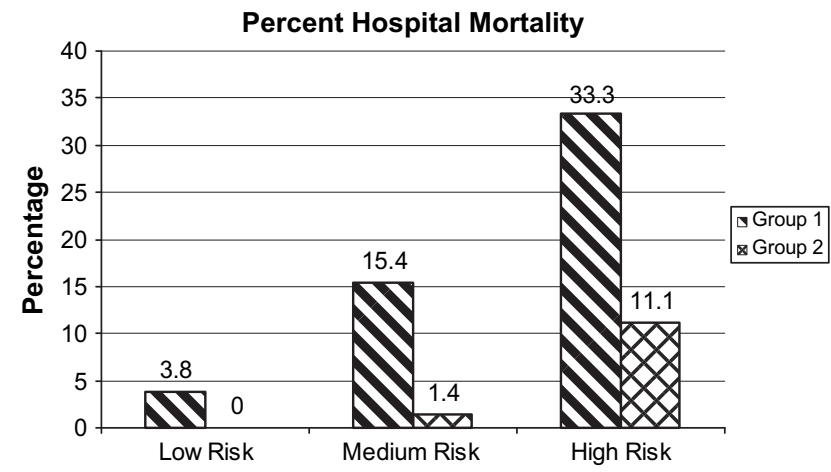

FIGURE 1. Impact of lymphopenia on mortality within risk groups. The $P$ values by Fisher's exact test were as follows: low-risk group, .19; the medium-risk group, .005; and the high-risk group, .34 . 

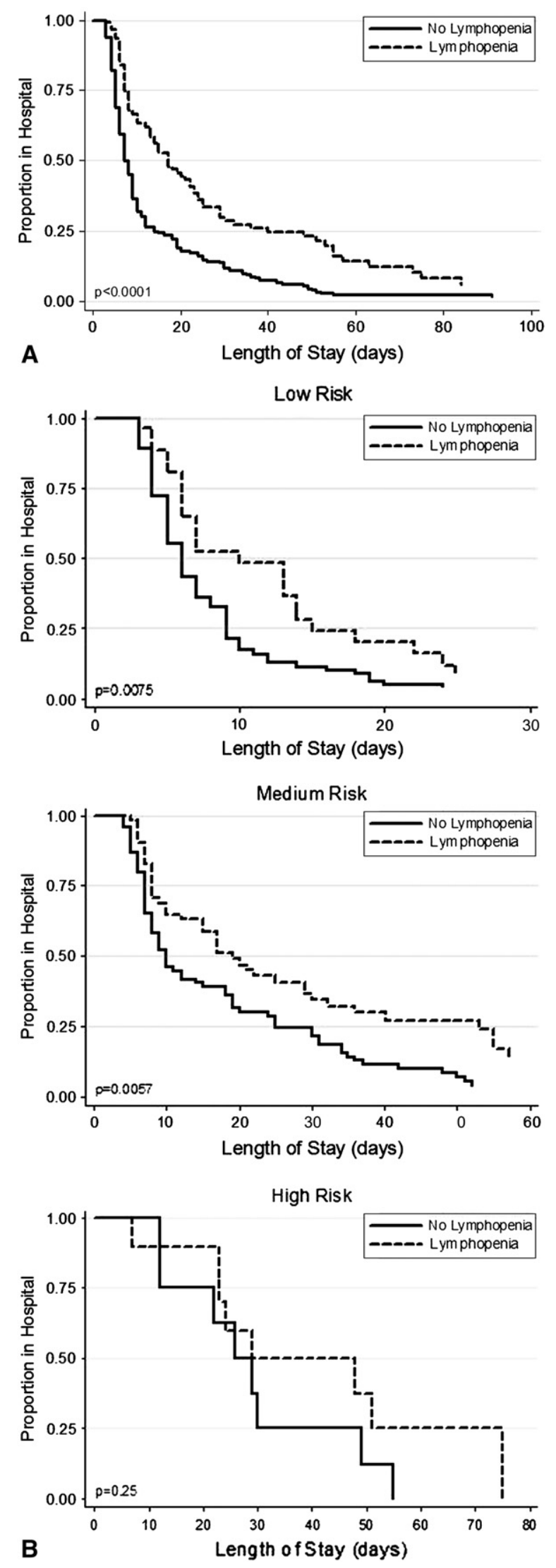

The RACHS-1 is a consensus-based method developed to allow meaningful comparisons of in-hospital mortality for children undergoing surgery for congenital heart disease ${ }^{16}$ that has been used to predict postoperative mortality (area under the ROC between 0.74 and 0.78 ) and hospital stay. ${ }^{15,17,19,23}$ The addition of age at operation has been shown to increase the ability of RACHS-1 to predict mortality to an area under the ROC of $0.81 .{ }^{19}$ Our study confirmed the above findings that younger age at operation and increased surgical complexity are powerful preoperative predictors of postoperative mortality and that the addition of lymphopenia to the model further enhances this predictive ability with area under the ROC increasing to 0.90 .

The causes of preoperative lymphopenia are likely multifactorial and broadly fall into 3 categories: increased destruction, decreased production, and lymphocyte loss secondary to sequestration or drainage.

Lymphopenia, along with young age and male sex, has been shown to be an important predictor of the need for active emergency room resuscitation and admission to pediatric intensive care units in infants less than 3 months of age. ${ }^{24}$ Stress response, manifested by elevated norepinephrine and cortisol levels, is associated with lymphopenia. ${ }^{11}$ Profound lymphopenia has also been recently associated with the sudden and rapid release of proinflammatory cytokines in voluntary individuals after the intravenous infusion of TGN1412, a novel superantagonist anti-CD28 monoclonal antibody that directly stimulates $\mathrm{T}$ cells. ${ }^{8}$ This rapid depletion is thought to be caused by apoptosis of both $\mathrm{B}$ and $\mathrm{T}$ lymphocytes, and inhibition of this apoptosis by caspase inhibitors has been proposed as a mechanism to enhance immunity. ${ }^{25}$ It is possible that patients with more chronic conditions, such as congestive heart failure, have a similar increase in lymphocyte apoptosis in response to raised levels of various inflammatory cytokines and chemokines. ${ }^{26}$ Deficiencies in factors necessary for lymphocyte growth and proliferation, such as zinc, may contribute to lymphopenia in patients with prolonged marginal nutrition. ${ }^{27}$ Another cause for lymphopenia in critically ill children may include use of the inotropic agent dopamine, which is known to suppress the production of prolactin, which is thought to play an important role in lymphocyte proliferation; its absence can lower the ALC. ${ }^{28}$ In our study, the patients with preoperative lymphopenia were more likely to be receiving higher doses of dopamine and other catecholamines. The threshold for lymphopenia-induced dopamine in critically ill patients has not been determined.

Congenital heart disease and decreased T-lymphocyte production secondary to thymic hypoplasia are seen together

FIGURE 2. A, Kaplan-Meier analysis of the association of length of stay between patients with and without preoperative lymphopenia. B, KaplanMeier analysis of the association of length of stay between patients with and without preoperative lymphopenia within risk categories. 

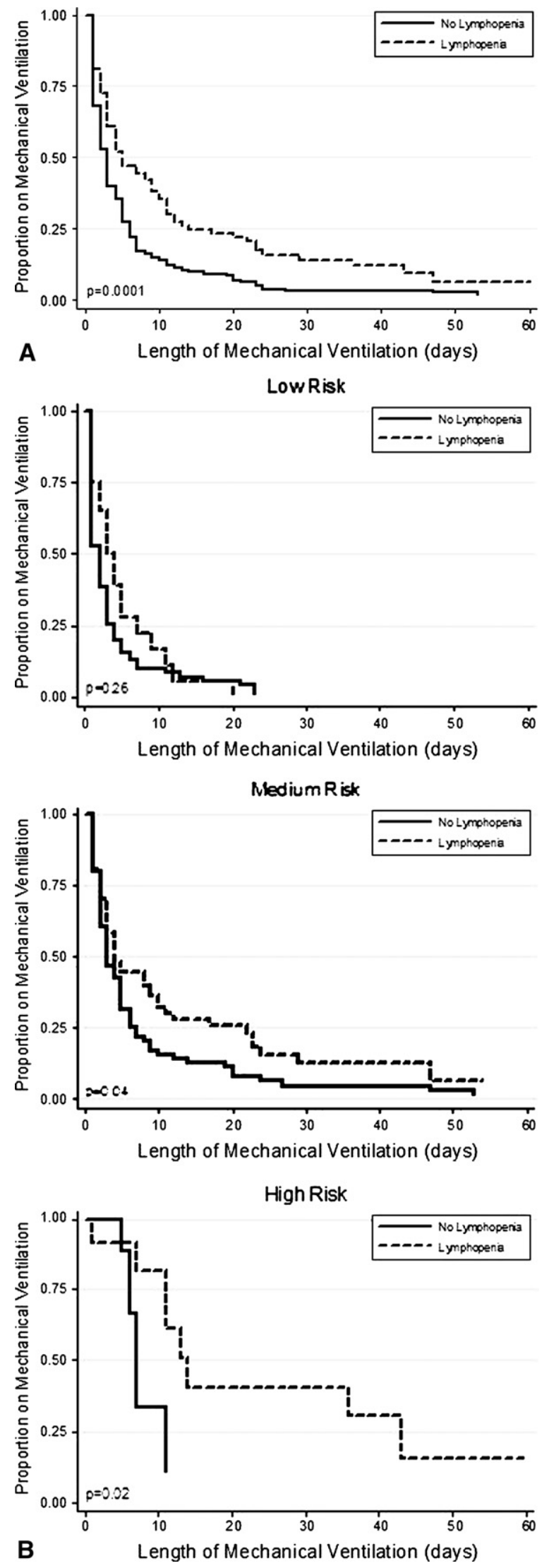

in DiGeorge syndrome-velocardiofacial syndrome (micro deletions of 22q11 or 10p13). ${ }^{2}$ Infants with Down syndrome are also thought to have a disturbance in their adaptive immunity inasmuch as they do not undergo the normal expansion of $\mathrm{T}$ and $\mathrm{B}$ lymphocytes seen in children without Down syndrome. Children with Down syndrome also have lower absolute $\mathrm{T}$ and $\mathrm{B}$ cell counts until at least 15 months of age, with some recovery in $\mathrm{T}$ cell population at older ages but continued depression in B lymphocyte count. ${ }^{29}$ In our study, lymphopenic patients were more likely to have known congenital anomalies including DiGeorge and Down syndromes.

Cardiac lesions associated with pulmonary venous obstruction, such as hypoplastic left heart syndrome or total anomalous pulmonary venous return, are also known to be associated with pulmonary lymphatic dysplasia. ${ }^{30-33}$ Surgery and inflammatory conditions can lead to secondary lymphatic dysplasia also. ${ }^{34}$ Some genetic syndromes, such as Turner syndrome, Noonan syndrome, LEOPARD syndrome (Lentigines, Electrocardiogram abnormalities, Ocular hyperteleorism, Pulmonary stenosis, Abnormal genitalia, Retardation of growth, Deafness), or Costello syndrome, are also associated with cardiac defects and lymphedema. Lymphedema seen in these children is a reflection of the inadequacy of the lymphatic system as a result of congenital lymphatic dysplasia. ${ }^{34-36}$ The filtered plasma proteins, lipids, and lymphocytes that normally leak from the bloodstream into the interstitium accumulate in the extracellular space as chyle. Chyle is rich in lymphocytes, triglycerides, and proteins including albumin and globulins. ${ }^{36}$ A larger proportion of the lymphopenic patients in our study were given low-fat formulas in the postoperative period, suggesting the clinical presence of chylous effusions. Although chylous effusions can certainly occur as a consequence of damage to the lymphatics during surgery, the higher incidence in patients who are lymphocytopenic preoperatively indicates that these effusions are likely a result of existing lymphatic dysplasia. The presence of pulmonary lymphangiectasia may explain the need for prolonged mechanical ventilation with higher settings and increased use of nitric oxide in our patients, which in turn leads to increased length of hospital stay.

Several limitations of our study should be considered while interpreting our results. The most complex congenital heart lesions, such as hypoplastic left heart syndrome and transposition of great arteries, are repaired in the early neonatal period to get the best outcomes. This leads to the strong, but nonlinear, relationship seen between age and high risk categories. ${ }^{19}$ We tried to minimize this selection

FIGURE 3. A, Kaplan-Meier analysis of the association of days on mechanical ventilation among patients with and without preoperative lymphopenia. B, Kaplan-Meier analysis of the association of length of mechanical ventilation between patients with and without preoperative lymphopenia within risk categories. 
bias by analyzing the data within risk categories and found a persistent effect of lymphopenia on outcomes. The presence of confounding variables in retrospective studies is a limitation. A stepwise logistic regression analysis showed that lymphopenic subjects were more likely to have congenital anomalies, higher preoperative inotrope scores, and lower preoperative albumin and creatinine levels. We tried to minimize the effect of the confounding variables by doing a multivariate analysis and by analyzing the data within risk categories also. The confounding preoperative variables suggest possible etiologies discussed above because we believe that lymphopenia is a sign, not the disease. We did analyze the lymphocyte count as a continuous variable in addition to the dichotomous analysis presented here with no difference in results. However, we did note that each drop in the ALC of 1000 cells $/ \mathrm{mm}^{3}$ results in an increase in the risk of mortality by 2.67 -fold. We do not know whether the decrease in lymphocytes is across all subsets of lymphocytes or whether particular subsets are more suppressed. Future studies are needed to investigate this in more detail. The presence of a relatively small number of patients in the RACHS-1 category 1 and absence of any patients in the RACHS- 1 category 5 group limited our ability to analyze the data; therefore, for the purposes of statistical analysis, we consolidated the RACHS-1 risk categories into the 3 groups (low-, medium-, and high-risk). The rarity of the two procedures listed in category 5 (neonatal repair of Ebstein anomaly and truncus arteriosus with interrupted aortic arch) is a well-known limitation of the RACHS-1 risk stratification. Another limitation introduced by the use of RACHS-1 was the exclusion of patients who underwent cardiac transplantation. Nine patients, who otherwise met the study inclusion criteria, underwent transplant during the study period at our center but were not included in the analysis.

In summary, the preoperative determination of lymphopenia in critically ill children with congenital heart disease is one of the predictors of postoperative death, need for prolonged hospital stay, need for increased postoperative respiratory support, and prolonged postoperative suppression of lymphocyte count. Presence of lymphopenia is accompanied by other changes in laboratory parameters such as hypoalbuminemia and elevated levels of serum creatinine as well as need for higher inotrope dose preoperatively and the presence of genetic/congenital anomaly. Thus, preoperative lymphopenia should be considered as a sign of underlying illness that could be a result of increased lymphocyte destruction such as is seen in systemic inflammatory response syndrome, decreased lymphocyte production as seen in DiGeorge syndrome, or due to increased loss from lymphatic dysplasia as seen in Noonan syndrome. We propose the addition of lymphopenia to the existing preoperative strategies for risk assessment and stratification.

\section{References}

1. Janeway CA Jr. How the immune system works to protect the host from infection: a personal view. Proc Natl Acad Sci U S A. 2001;98:7461-8.

2. Buckley RH. Primary cellular immunodeficiencies. J Allergy Clin Immunol. 2002;109:747-57.

3. Moir S, Fauci AS. Pathogenic mechanisms of B-lymphocyte dysfunction in HIV disease. J Allergy Clin Immunol. 2008;122:12-9; quiz 20-1.

4. Beers MH, Porter RS, Jones TVK, eds. The Merck manual of diagnosis and therapy. 18th ed. Whitehouse Station (NJ): Merck Research Laboratories, Division of Merck \& Co, Inc; 2006.

5. Denny T, Yogev R, Gelman R, Skuza C, Oleske J, Chadwick E, et al. Lymphocyte subsets in healthy children during the first 5 years of life. JAMA. 1992;267: 1484-8.

6. Kotylo PK, Fineberg NS, Freeman KS, Redmond NL, Charland C. Reference ranges for lymphocyte subsets in pediatric patients. Am J Clin Pathol. 1993;100:111-5.

7. Shearer WT, Rosenblatt HM, Gelman RS, Oyomopito R, Plaeger S, Stiehm ER, et al. Lymphocyte subsets in healthy children from birth through 18 years of age: the Pediatric AIDS Clinical Trials Group P1009 study. J Allergy Clin Immunol. 2003; 112:973-80.

8. Suntharalingam G, Perry MR, Ward S, Brett SJ, Castello-Cortes A, Brunner MD, et al. Cytokine storm in a phase 1 trial of the anti-CD28 monoclonal antibody TGN1412. N Engl J Med. 2006;355:1018-28.

9. Huehnergarth KV, Mozaffarian D, Sullivan MD, Crane BA, Wilkinson CW, Lawler RL, et al. Usefulness of relative lymphocyte count as an independent predictor of death/urgent transplant in heart failure. Am J Cardiol. 2005;95: 1492-5.

10. Ommen SR, Hammill SC, Gibbons RJ. The relative lymphocyte count predicts death in patients receiving implantable cardioverter defibrillators. Pacing Clin Electrophysiol. 2002;25:1424-8.

11. Ommen SR, Hodge DO, Rodeheffer RJ, McGregor CG, Thomson SP, Gibbons RJ. Predictive power of the relative lymphocyte concentration in patients with advanced heart failure. Circulation. 1998;97:19-22.

12. Hotchkiss RS, Tinsley KW, Swanson PE, Schmieg RE Jr, Hui JJ, Chang KC, et al. Sepsis-induced apoptosis causes progressive profound depletion of B and CD4+T lymphocytes in humans. J Immunol. 2001;166:6952-63.

13. Felmet KA, Hall MW, Clark RS, Jaffe R, Carcillo JA. Prolonged lymphopenia, lymphoid depletion, and hypoprolactinemia in children with nosocomial sepsis and multiple organ failure. J Immunol. 2005; 174:3765-72.

14. Bocsi J, Hambsch J, Osmancik P, Schneider P, Valet G, Tarnok A. Preoperative prediction of pediatric patients with effusions and edema following cardiopulmonary bypass surgery by serological and routine laboratory data. Crit Care. 2002;6:226-33.

15. Boethig D, Jenkins KJ, Hecker H, Thies WR, Breymann T. The RACHS-1 risk categories reflect mortality and length of hospital stay in a large German pediatric cardiac surgery population. Eur J Cardiothorac Surg. 2004;26:12-7.

16. Jenkins KJ, Gauvreau K, Newburger JW, Spray TL, Moller JH, Iezzoni LI. Consensus-based method for risk adjustment for surgery for congenital heart disease. $J$ Thorac Cardiovasc Surg. 2002;123:110-8.

17. Larsen SH, Pedersen J, Jacobsen J, Johnsen SP, Hansen OK, Hjortdal V. The RACHS-1 risk categories reflect mortality and length of stay in a Danish population of children operated for congenital heart disease. Eur J Cardiothorac Surg. 2005;28:877-81.

18. Definition for Acute Renal Failure-Workgroup 1 report. Acute Dialysis Quality Initative; 2002; Vincenza, Italy. ADQI.

19. Kang N, Cole T, Tsang V, Elliott M, de Leval M. Risk stratification in paediatric open-heart surgery. Eur J Cardiothorac Surg. 2004;26:3-11.

20. Roberts N, Westrope C, Pooboni SK, Mulla H, Peek GJ, Sosnowski AW, et al. Venovenous extracorporeal membrane oxygenation for respiratory failure in inotrope dependent neonates. ASAIO J. 2003;49:568-71.

21. Brown KL, Ridout DA, Goldman AP, Hoskote A, Penny DJ. Risk factors for long intensive care unit stay after cardiopulmonary bypass in children. Crit Care Med. 2003;31:28-33

22. Gillespie M, Kuijpers M, Van Rossem M, Ravishankar C, Gaynor JW, Spray T, et al. Determinants of intensive care unit length of stay for infants undergoing cardiac surgery. Congenit Heart Dis. 2006;1:152-60.

23. Kang N, Tsang VT, Elliott MJ, de Leval MR, Cole TJ. Does the Aristotle Score predict outcome in congenital heart surgery? Eur J Cardiothorac Surg. 2006;29:986-8.

24. Adamski JK, Arkwright PD, Will AM, Patel L. Transient lymphopenia in acutely unwell young infants. Arch Dis Child. 2002;86:200-1.

25. Hotchkiss RS, Chang KC, Swanson PE, Tinsley KW, Hui JJ, Klender P, et al. Caspase inhibitors improve survival in sepsis: a critical role of the lymphocyte. Nat Immunol. 2000;1:496-501. 
26. Yndestad A, Damas JK, Oie E, Ueland T, Gullestad L, Aukrust P. Systemic inflammation in heart failure - the whys and wherefores. Heart Fail Rev. 2006;11:83-92.

27. Fraker PJ, King LE, Laakko T, Vollmer TL. The dynamic link between the integrity of the immune system and zinc status. J Nutr. 2000;130(5S Suppl):1399S-406S.

28. Clevenger CV, Altmann SW, Prystowsky MB. Requirement of nuclear prolactin for interleukin-2 - stimulated proliferation of T lymphocytes. Science. 1991;253:77-9.

29. de Hingh YC, van der Vossen PW, Gemen EF, Mulder AB, Hop WC, Brus F, et al. Intrinsic abnormalities of lymphocyte counts in children with Down syndrome. J Pediatr. 2005;147:744-7.

30. Luciani GB, Pessotto R, Mombello A, Mazzucco A. Hypoplastic left heart syndrome with restrictive atrial septal defect and congenital pulmonary lymphangiectasis. Cardiovasc Pathol. 1999;8:49-51.

31. Maeda K, Yamaki S, Kado H, Asou T, Murakami A, Takamoto S. Hypoplasia of the small pulmonary arteries in hypoplastic left heart syndrome with restrictive atrial septal defect. Circulation. 2004;110(11 Suppl. 1):II139-46.
32. Moerman PL, Van Dijck H, Lauweryns JM, Eggermont E, Van der Hauwaert LG Premature closure of the foramen ovale and congenital pulmonary cystic lymphangiectasis in aortic valve atresia or in severe aortic valve stenosis. Am J Cardiol. 1986;57:703-5.

33. Weldner PW, Myers JL, Gleason MM, Cyran SE, Weber HS, White MG, et al. The Norwood operation and subsequent Fontan operation in infants with complex congenital heart disease. J Thorac Cardiovasc Surg. 1995; 109:654-62.

34. The diagnosis and treatment of peripheral lymphedema. Consensus document of the International Society of Lymphology. Lymphology. 2003;36:84-91.

35. Barker PM, Esther CR Jr, Fordham LA, Maygarden SJ, Funkhouser WK. Primary pulmonary lymphangiectasia in infancy and childhood. Eur Respir J. 2004;24: 413-9.

36. Esther CR Jr, Barker PM. Pulmonary lymphangiectasia: diagnosis and clinical course. Pediatr Pulmonol. 2004;38:308-13. 